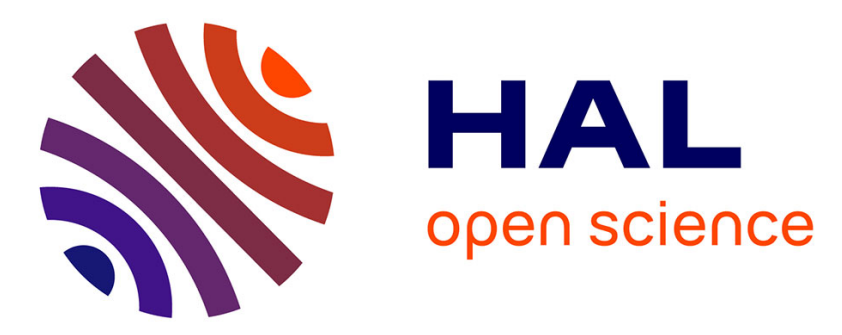

\title{
Influence of the Masking Material and Geometry on the 4H-SiC RIE Etched Surface State
}

Mihai Lazar, Fabrice Enoch, Farah Laariedh, Dominique Planson, Pierre

Brosselard

\section{- To cite this version:}

Mihai Lazar, Fabrice Enoch, Farah Laariedh, Dominique Planson, Pierre Brosselard. Influence of the Masking Material and Geometry on the 4H-SiC RIE Etched Surface State. CSCRM, Aug 2010, Oslo, Norway. pp.477-480, 10.4028/www.scientific.net/MSF.679-680.477 . hal-00661443

\section{HAL Id: hal-00661443 https://hal.science/hal-00661443}

Submitted on 9 May 2019

HAL is a multi-disciplinary open access archive for the deposit and dissemination of scientific research documents, whether they are published or not. The documents may come from teaching and research institutions in France or abroad, or from public or private research centers.
L'archive ouverte pluridisciplinaire HAL, est destinée au dépôt et à la diffusion de documents scientifiques de niveau recherche, publiés ou non, émanant des établissements d'enseignement et de recherche français ou étrangers, des laboratoires publics ou privés. 


\title{
Influence of the masking material and geometry on the 4H-SiC RIE etched surface state
}

\author{
Mihai Lazar ${ }^{\mathrm{a}}$, Fabrice Enoch ${ }^{\mathrm{b}}$, Farah Laariedh ${ }^{\mathrm{c}}$, Dominique Planson ${ }^{\mathrm{d}}$ and \\ Pierre Brosselard ${ }^{\mathrm{e}}$ \\ ${ }^{1}$ Lab. AMPERE, UMR CNRS 5005, INSA-Lyon, Bât. L. VINCI, 69621 Villeurbanne Cedex, France \\ amihai.lazar@insa-lyon.fr, ${ }^{b}$ fabrice.enoch@insa-lyon.fr, ${ }^{\circ}$ farah.laariedh@insa-lyon.fr, \\ dominique.planson@insa-lyon.fr, epierre.brosselard@insa-lyon.fr
}

Keywords: Micromasking, reactive ion etching, volatility, scanning electronic microscopy

\begin{abstract}
The roughness of etched $\mathrm{SiC}$ surfaces must be minimized to obtain surfaces with a smooth aspect, avoiding micromasking artifacts originating from re-deposited particles during the etching process. Four varieties of masks, $\mathrm{Al}, \mathrm{Ni}, \mathrm{Si}$ and $\mathrm{C}$, were deposited on the $\mathrm{SiC}$ surface by photolithographic process. The $\mathrm{C}$ structures were formed by annealing conversion of patterned thick photoresist. On these surfaces, dry etching was performed with an $\mathrm{SF}_{6} / \mathrm{O}_{2}$ plasma produced in a Reactive-Ion-Etching (RIE) reactor. Although a better aspect of the surface is obtained with Ni in comparison with $\mathrm{Al}$ mask, micromasking could also occur even with $\mathrm{Ni}$ if the mask design was not enough spaced out. With $\mathrm{C}$ and $\mathrm{Si}$ masks, which produce fluorides species with negative boiling temperature, smooth etched surface was obtained without micromasking, even for tight masks covering up to $90 \%$ of the $\mathrm{SiC}$ surface.
\end{abstract}

\section{Introduction}

Silicon carbide device process requires a local $\mathrm{SiC}$ etching by dry process, due to the strong inter-atomic Si-C bonds. A photolithographic process is applied by patterning a mask at the $\mathrm{SiC}$ wafer surface. The mask is locally opened to form the zones to be etched. Different masks are utilized, their nature and thickness being determined by the etching depth in SiC, plasma chemistry induced by the mask presence, and the selectivity, i.e. the ratio between the SiC etching depth and the mask consumed. SiC etching is usually performed with fluorinated plasma chemistry, few results being published with chlorides plasma chemistries. Fluorinated plasma are prefered due to the higher etching rates obtained in this case.

In order to fabricate power and high temperature devices, the roughness of the etched areas must be minimized to a smooth aspect close to the initial state. Rough surfaces increase locally the electric field, generating leakage current and decreasing the breakdown voltage of the junctions.

Micromasking artifacts originate from re-deposited particles which locally reduce etching and lead to rough surfaces with a grass aspect (also named "black silicon" zones in Si etching studies) and a relief of pillar - column. Figure 1 presents examples of etched SiC surfaces with micromasking artifacts. In Figure 1a micromasking is produced by deposited particles extracted from the mask close to an etched trench. In Figure 1b, a more uniform micromasking repartition is shown, the re-deposited particles being in provenance of the cathode electrode made in Al.

In this paper we present results that show how to control the micromasking phenomenon during local etching of the $\mathrm{SiC}$ by choosing an adequate mask that is patterned in order to delimit the areas to be etched. This experimental study should be also helpful for works on micro-nanostructures that need to manage rough surfaces [1].

\section{Experimental}

4H-SiC samples with a surface area of $5 \mathrm{~cm}^{2}$ were cut from 3 inches diameter SiCrystal wafers. Four varieties of masks, $\mathrm{Al}, \mathrm{Ni}, \mathrm{Si}$ and $\mathrm{C}$, were formed on the $\mathrm{SiC}$ surface by photolithographic 
process. Al, Ni and Si have been deposited by electron-beam evaporation. Structures have been patterned by lift-off process, using a reversible photoresist for the $\mathrm{Ni}$, wet etching with positive photoresist mask for the $\mathrm{Al}$ and dry etching with positive photoresist mask for the $\mathrm{Si}$. The $\mathrm{C}$ structures were formed by annealing conversion at $600^{\circ} \mathrm{C}$ during $30 \mathrm{~min}$ of patterned thick $(\sim 10 \mu \mathrm{m})$ AZ nLOF 2070 photoresist.
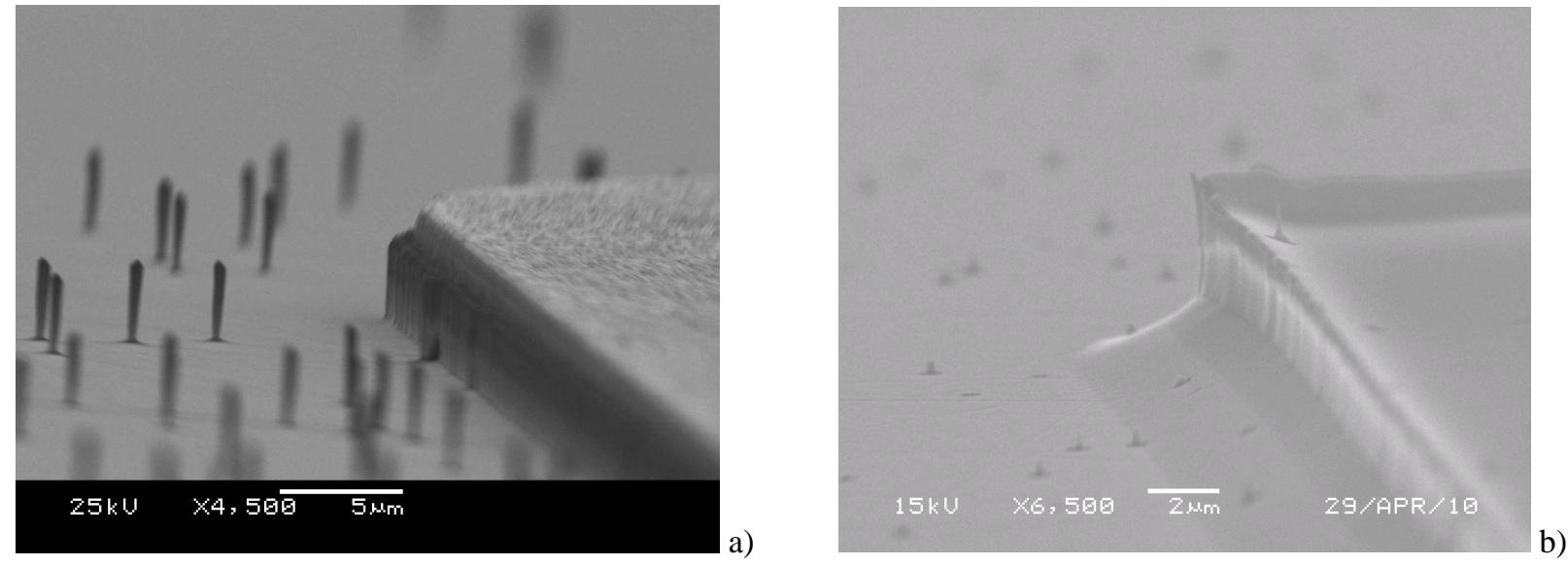

Fig. 1. Examples of micromasking artifacts produced by deposited particles extracted from the mask close to an etched trench (a) and from the cathode electrode made in Al (b).

On these $\mathrm{SiC}$ surfaces partially covered with the mentioned masks, dry etching was performed with an $\mathrm{SF}_{6} / \mathrm{O}_{2}$ plasma chemistry produced in an Alcatel Nextral NE110, a Reactive-Ion-Etching (RIE) reactor with a plasma source generated at $13.56 \mathrm{MHz}$ and a quartz cathode electrode of 4 inches diameter. Particular attention was paid in order to obtain accurate and reproducible processes, by cleaning and passivating the reactor before the $\mathrm{SiC}$ samples etching, as well as keeping the reflected power in the reactor at minimal values and protecting the quartz cathode. The plasma parameters (power, pressure, gas flows) were defined in order to obtain a relatively high etching rate of the $\mathrm{SiC}, 0.2$ to $0.33 \mu \mathrm{m} / \mathrm{min}$ [2], avoiding thus "trenching" phenomenon on sharp bottom corners [3].
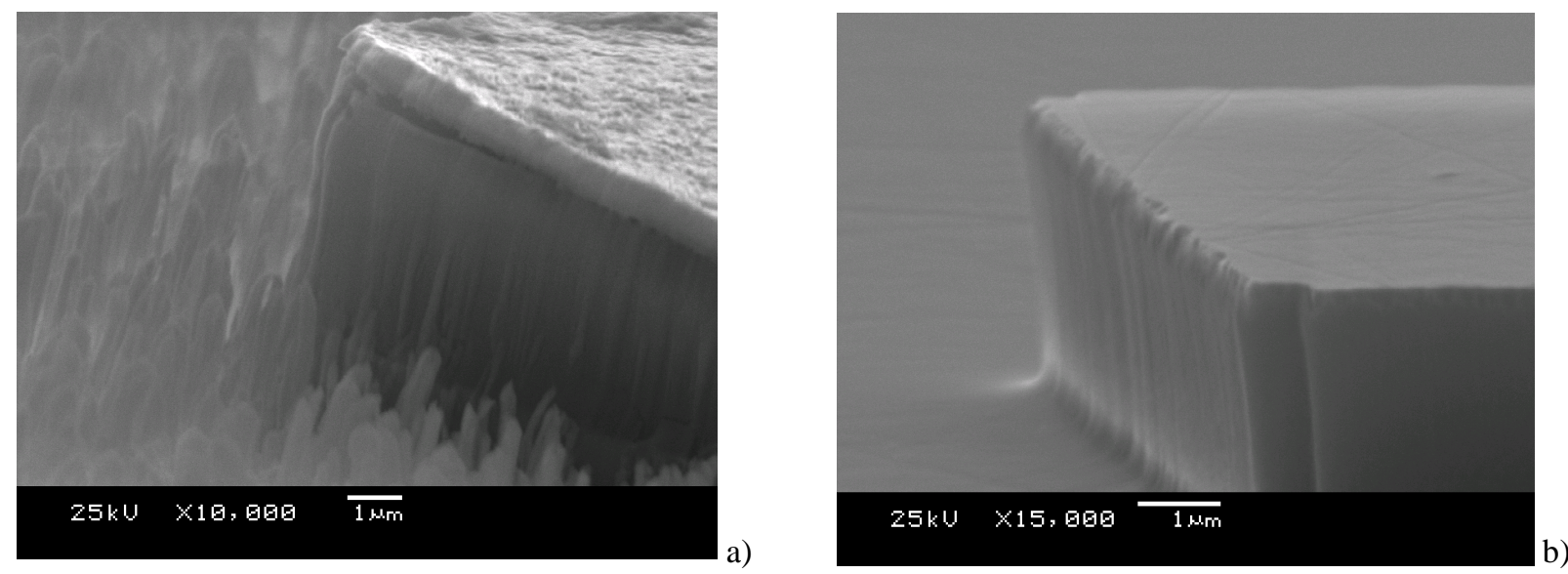

Fig. 2. 4H-SiC surfaces after RIE etching: (a) a rough SiC surface with grass aspect, (b) smooth SiC surface obtained with a Ni mask

The morphology of the etched patterns was characterized by scanning electron microscopy (SEM) observations and the etching depth and mask thickness were measured using a Tencor Alpha Step 500 profilometer.

\section{Results and discussions}


Fig. 2 presents SEM micrographs of locally etched 4H-SiC surfaces. On the left (Fig.2a), a rough $\mathrm{SiC}$ surface is obtained, typical of those obtained with $\mathrm{Al}$ mask when the micromasking phenomenon occurs. On the right (Fig 2b) a smooth surface is obtained, like in the non etched area that can be observed at the top of the trenches where mask were removed. In this case we used a $\mathrm{Ni}$ mask that covered $35 \%$ of the SiC surface.

Despite the better aspect of the surface obtained with $\mathrm{Ni}$ in comparison with $\mathrm{Al}$ mask (using the same mask geometry for the $\mathrm{Ni}$ and $\mathrm{Al}$ ), micromasking could also occur even for $\mathrm{Ni}$ if the mask design was not enough spaced out. This means a low coverage of the $\mathrm{SiC}$ surface is needed, as well as a spaced distribution of the patterns, allowing non volatile species produced by the RIE plasma to evacuate.

Table 1. Melting and boiling temperature of RIE reaction products.

\begin{tabular}{cccc}
\hline Element & Reac. Prod. & Melting Temp. $\left({ }^{\circ} \mathrm{C}\right)$ & Boiling Temp $\left({ }^{\circ} \mathrm{C}\right)$ \\
\hline $\mathrm{Al}$ & $\mathrm{AlF}_{3}$ & 1297 & \\
& $\mathrm{Al}_{2} \mathrm{O}_{3}$ & 2072 & 2977 \\
$\mathrm{Ni}$ & $\mathrm{NiF}_{2}$ & 1370 & 1750 \\
& $\mathrm{NiSO}_{4}$ & 100 & 840 \\
$\mathrm{C}$ & $\mathrm{CF}_{4}$ & -183.6 & -127.8 \\
$\mathrm{Si}$ & $\mathrm{SiF}_{4}$ & -121 & -38 \\
\hline
\end{tabular}

Table 1 shows the melting and boiling temperatures of the species produced by the $\mathrm{RIE} \mathrm{SF}_{6} / \mathrm{O}_{2}$ reaction on the masks. These values are directly related to the volatility of these species during the $\mathrm{SiC}$ etching. Comparing $\mathrm{Ni}$ to $\mathrm{Al}$, if high and close values correspond to the fluorides species $\left(\mathrm{NiF}_{2}\right.$ and $\mathrm{AlF}_{3}$ ), Ni chemical compounds with lower boiling temperature values can be produced. This may explain the smoother surface obtained with the Ni masks. Nevertheless, open mask geometry is needed to avoid deposition of $\mathrm{Ni}$ non volatile species $\left(\right.$ as $\mathrm{NiF}_{2}$ ) on the $\mathrm{SiC}$ surface, that leads to micromaking during the etching process.
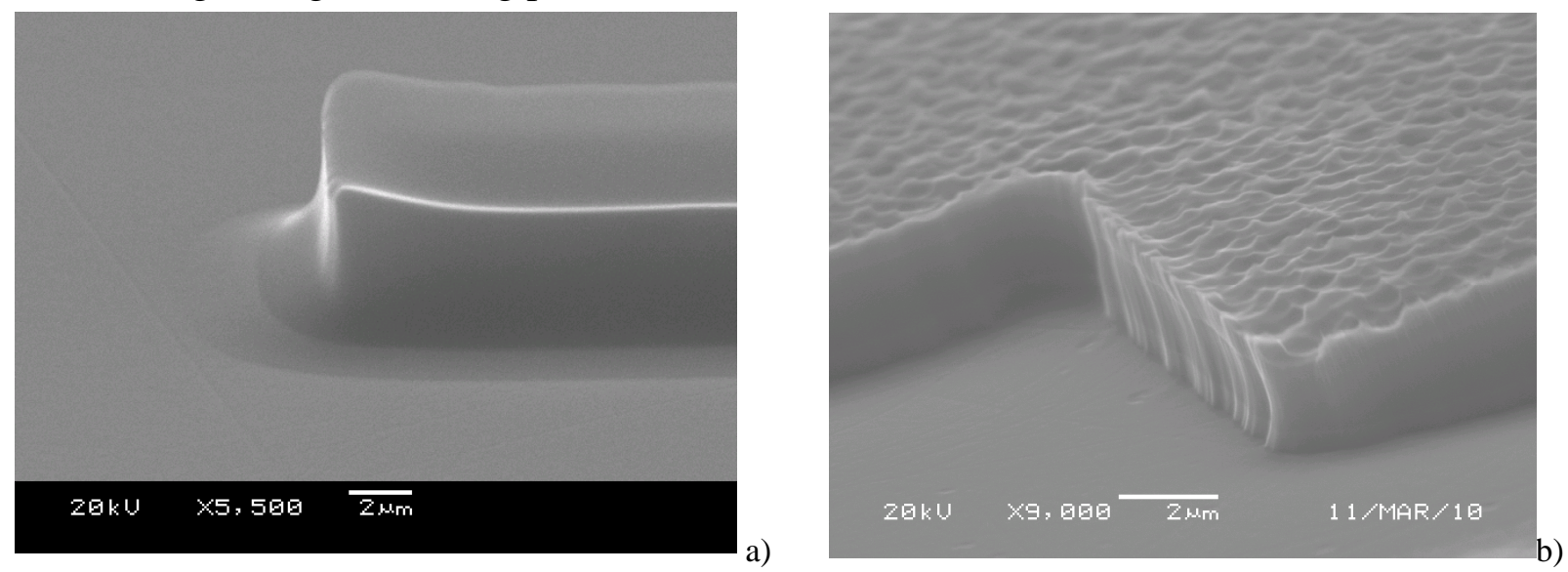

Fig. 3. 4H-SiC surfaces after RIE etching with C mask (a) and Si mask (b)

We notice that $\mathrm{C}$ and $\mathrm{Si}$ masks produce fluorides species with negative boiling temperature (table 1). With such masks, covering up to $90 \%$ of the SiC samples surface, we obtained smooth etched surface without micromasking. SEM micrographs are presented in the Fig. $3 \mathrm{a}$ and $3 \mathrm{~b}$ for the SiC samples etched with $\mathrm{C}$ respectively masks and $\mathrm{Si}$ masks.

The photomasks geometries used for the lithographic definition of the $\mathrm{Ni}, \mathrm{Si}$ and $\mathrm{C}$ mask structures at the $\mathrm{SiC}$ sample's surfaces are presented in figure 4. The dark-grey zones represent the non etched, mask-protected surface and the white-clear zones correspond to the $\mathrm{SiC}$ etched areas. The design of the Ni mask shown on Figure 4 a covered $35 \%$ of the SiC surface, while Si and $\mathrm{C}$ masks covered up to $90 \%$ of the surface (Figure $4 b$ ).

However, compared to the $\mathrm{Ni}$, the selectivity of $\mathrm{Si}$ and $\mathrm{C}$ masks are significantly lower. The selectivity of $\mathrm{SiC}$ to $\mathrm{Ni}$ mask was $40-50: 1$, and $0.5-2: 1$ to $\mathrm{C}$ or Si masks. The etching depth on the 
$\mathrm{SiC}$ is limited by the mask's consumption during the process. Thus, $\mathrm{Si}$ and $\mathrm{C}$ masks can be utilized to etch tight structures (limited in the depth to a few $\mu \mathrm{m}$ ) to fabricate high temperature, low voltage, on-chip integrated control circuitry [4]. On the other hand Ni masks are suitable to etch the deeper trenches (up to tens of $\mu \mathrm{m}$ ) required to fabricate vertical high power SiC devices. In this case, however, the structures must be spaced enough in order to evacuate the non-volatile species.
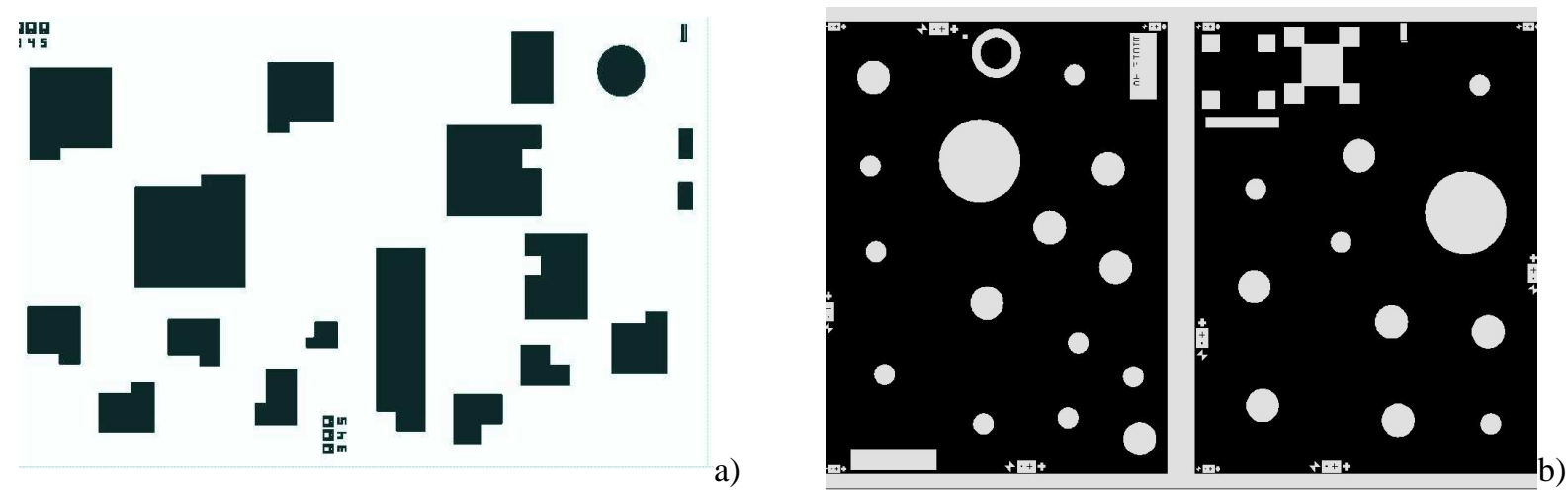

Fig. 4. Photomasks geometries used for the lithographic definition of the $N i(a)$, Si and $C(b)$ mask structures. Field sizes are 6 by $10 \mathrm{~mm}^{2}$.

We also notice, for the samples etched with the $\mathrm{C}$ mask (Fig 3a), a tapered transition at the bottom trenches, due to the initial geometry of the $\mathrm{C}$ mask, with tilted walls formed during the annealing conversion of the photoresist. This geometry could be used in the design of new SiC devices with sloped mesa structures.

\section{Conclusion}

Managing SiC surfaces in order to fabricate discrete or integrated devices requires to choose an appropriate mask (in terms of geometry and nature). When deep SiC etched structures are needed, Ni mask can be used thanks to its high selectivity, if particular attention is paid to limit the micromasking phenomenon by increasing the space between structures. With negative boiling temperatures of the fluorides species produced during the RIE reaction, $\mathrm{C}$ or $\mathrm{Si}$ are a better option for structures with confined surfaces, like interdigitated fingers of $\mathrm{SiC}$ switches. The $\mathrm{C}$ mask allows also to obtain sloped trenches which can for example facilitate making contacts.

Conversely, the non-volatile species produced from the $\mathrm{Ni}$ or $\mathrm{Al}$ masks can be used to increase the roughness of the $\mathrm{SiC}$ surface and to control the generation of new $\mathrm{SiC}$ micro-nanostructures.

\section{Acknowledgments}

The authors gratefully thank Nanolyon platform team (Pierre Cremillieu, Jean-Louis Leclercq and Radoslaw Mazurczyk) for technological means availability and for training our staff. The authors would also like to thank the financial support of ANR-USAR under the "VHVD-SiC" project.

\section{References}

[1] R. Dussart, X Mellhaoui, T Tillocher, P Lefaucheux, M Volatier, C Socquet-Clerc, P Brault and P Ranson: J. Phys. D: Appl. Phys. Vol. 38 (2005), p. 3395.

[2] M. Lazar, H. Vang, P. Brosselard, C. Raynaud, P. Cremillieu, J.-L. Leclercq, A. Descamps, S. Scharnholz, D. Planson: Superlattice and Microstructures Vol. 40 (2006), p. 388.

[3] F. Simescu, D. Coiffard, M. Lazar, P. Brosselard and D. Planson: J Optoelectron Adv M Vol. 12, 766 (2010), p. 766.

[4] I. Sankin, V. Bonderko, R. Kellev, J.B. Casady: Mater Sci Forum Vol. 527-29 (2006), p. 1207. 